Atmos. Chem. Phys., 13, 10847-10857, 2013

www.atmos-chem-phys.net/13/10847/2013/

doi:10.5194/acp-13-10847-2013

(c) Author(s) 2013. CC Attribution 3.0 License.

\title{
A climatology of formation conditions for aerodynamic contrails
}

\author{
K. Gierens and F. Dilger \\ Deutsches Zentrum für Luft- und Raumfahrt, Institut für Physik der Atmosphäre, Oberpfaffenhofen, Germany \\ Correspondence to: K. Gierens (klaus.gierens@dlr.de)
}

Received: 30 April 2013 - Published in Atmos. Chem. Phys. Discuss.: 5 June 2013

Revised: 8 October 2013 - Accepted: 11 October 2013 - Published: 7 November 2013

\begin{abstract}
Aircraft at cruise levels can cause two kinds of contrails, the well known exhaust contrails and the less wellknown aerodynamic contrails. While the possible climate impact of exhaust contrails has been studied for many years, research on aerodynamic contrails began only a few years ago and nothing is known about a possible contribution of these ice clouds to climate impact. In order to make progress in this respect, we first need a climatology of their formation conditions and this is given in the present paper.

Aerodynamic contrails are defined here as line shaped ice clouds caused by aerodynamically triggered cooling over the wings of an aircraft in cruise which become visible immediately at the trailing edge of the wing or close to it. Effects at low altitudes like condensation to liquid droplets and their potential heterogeneous freezing are excluded from our definition. We study atmospheric conditions that allow formation of aerodynamic contrails. These conditions are stated and then applied to atmospheric data: first to a special case where an aerodynamic contrail was actually observed and then to a full year of global reanalysis data. We show where, when (seasonal variation), and how frequently (probability) aerodynamic contrails can form, and how this relates to actual patterns of air traffic. We study the formation of persistent aerodynamic contrails as well. Furthermore, we check whether aerodynamic and exhaust contrails can coexist in the atmosphere. We show that visible aerodynamic contrails are possible only in an altitude range between roughly 540 and $250 \mathrm{hPa}$, and that the ambient temperature is the most important parameter, not the relative humidity. Finally, we argue that currently aerodynamic contrails have a much smaller climate effect than exhaust contrails, which may however change in future with more air traffic in the tropics.
\end{abstract}

\section{Introduction}

It is well known that aviation contributes to climate change and that a significant share of this contribution stems from persistent contrails and contrail cirrus (Lee et al., 2009). Aircraft produce contrails because the water vapour resulting from kerosene combustion cools in the expanding exhaust plume and may condense and freeze under sufficiently cold conditions (Schumann, 1996). The climate effect of exhaust contrails has been investigated for many years (see Lee et al., 2012, and references therein) and even estimates of the effect of contrail cirrus have become available (Burkhardt and Kärcher, 2011). Apart from exhaust contrails, aircraft cause other condensation effects as well (Gierens et al., 2009); at cruise levels they may produce aerodynamic contrails that originate in the airflow over the wings instead of the exhaust air. Aerodynamic contrails form preferentially in warmer air than exhaust contrails and are in this sense a complementary phenomenon (Kärcher et al., 2009). Research on aerodynamic contrails only began a few years ago when aerodynamic conditions (Gierens et al., 2009) and microphysical processes and optical effects (Kärcher et al., 2009) had been studied for the first time. The only further study on aerodynamic contrails was (to our knowledge) a case study where the meteorological conditions that led to formation of an aerodynamic contrail have been examined (Gierens et al., 2011). Evidently, aerodynamic contrails may add to aviation's climate impact (Kärcher et al., 2009), but this impact is not known up to now. In order to make progress in this respect, we need a climatology of aerodynamic contrails, and in order to achieve this we first need to formulate their formation conditions in meteorological terms and apply those conditions to climatological data. This is the topic and goal of the present paper. 
When air flows around the wings of an aircraft it is accelerated, and because of conservation of total enthalpy (the sum of kinetic energy and enthalpy) it cools as the flow gets faster. This cooling implies the rising of the relative humidity of the air, an effect that is quite strong at aviation cruise levels, such that condensation and freezing can occur even in relatively dry (say $\mathrm{RHi} \approx 20 \%$ ) ambient air (Gierens et al., 2009). If this happens in ice (super) saturated air the formed ice crystals stay in the atmosphere and may grow. If crystal growth is sufficient and quick enough such that the ice causes a visible effect directly behind the aircraft then there is an aerodynamic contrail (in the following occasionally abbreviated as AerC) which can be distinguished from exhaust contrails once it causes pretty iridescence effects (Gierens et al., 2011).

Although air is always cooling in this way once it flows around an aircraft wing and although the effect on relative humidity is quite strong at cruise levels, occurrences of aerodynamic contrails are rarely reported, at least compared to exhaust contrails. There are several reasons for this. For instance, it is hard to distinguish the two types of contrails for an observer at ground because iridescence effects occur only when the viewing angle between the sun and the contrail is relatively small (less than $30^{\circ}$ ). The exact point of onset of the contrail is hard to see from ground (at the wing: aerodynamic, at or behind the aircraft tail: exhaust contrail). Ice crystals once formed must grow to a size comparable to the wavelength of light ( 350 to $700 \mathrm{~nm}$ ) and this requires that the air has sufficient water vapour concentration. Since the latter decreases roughly exponentially with altitude throughout the troposphere it is often too dry at the higher cruise levels to form a visible aerodynamic contrail (Kärcher et al., 2009). At lower cruise levels, if it is too warm, the condensation over the wing might not be followed by freezing, and the tiny droplets will immediately evaporate once the air temperature relaxes back to its ambient value after the passage of the aircraft. Contrary to ice crystals which can survive and grow in ice supersaturated but otherwise clear air, water droplets would only survive in water saturated air which is never clear but always a cloud. Thus aerodynamic droplet formation (without freezing) with stable droplets could only happen within water clouds and thus remain invisible to the human eye. There may be other effects (e.g. higher droplet number concentration, similar to ship tracks) that might be detectable for suitable instruments, but such effects, if they exist at all, should not be labelled aerodynamic contrails. Finally, in situations where aerodynamic and exhaust contrails coexist, the aerodynamic contrail can hardly be seen since it is usually too faint against the exhaust contrail.

Thus we use the following working definition of aerodynamic contrails in the present paper: Aerodynamic contrails are line shaped ice clouds caused by the aerodynamically triggered cooling over the wings of an aircraft in cruise. They are visible immediately at the trailing edge of the wing or close to it. This definition serves two purposes, namely to suppress cloud formation effects that are not clearly related to an aerodynamic effect and to suppress effects that only involve liquid droplets. For instance, an invisible aerodynamic contrail can become visible later when it gets into an uplifting airmass. This is not an aerodynamic contrail according to our definition. A variety of aerodynamically triggered condensation effects occurs at low levels in the atmosphere, but we do not call them aerodynamic contrails since they probably consist of liquid water and the word contrail usually implies a phenomenon occurring at cruise levels. For practical reasons we will also exclude ice clouds formed by heterogeneous freezing at temperatures above the supercooling limit of liquid water, $T>235 \mathrm{~K}$. Heterogeneous freezing leads to relatively low crystal concentrations which may often not suffice for visibility, and it is not clear whether a heterogenous freezing process would be quick enough such that an ice cloud could appear close to the aircraft wing.

Obviously, aerodynamic contrail formation requires the atmosphere to be in a special state and in this paper we will study where, when, and how frequent such appropriate conditions occur. This is a necessary step towards assessment of the role of aerodynamic contrails in climate.

\section{Atmospheric conditions for aerodynamic contrails}

The ice crystals that constitute an aerodynamic contrail form from liquid aerosol particles that exist in copious numbers in the atmosphere. If the airflow around an airfoil is cooled to at least the supercooling limit for pure water, i.e. $235 \mathrm{~K}$ or $-38^{\circ} \mathrm{C}$, then the liquid aerosol droplets can freeze, and the ice crystals formed can remain in the atmosphere for a while when the air is ice-supersaturated. Aerodynamic contrail formation happens but does not lead to a visible contrail if the ambient air is colder than approximately $230 \mathrm{~K}$ (Kärcher et al., 2009, their Fig. 3). Ice crystals need to reach a radius of about $100 \mathrm{~nm}$ to become visible because Miescattering gets effective only when the scatterer's "perimeter" (i.e. $2 \pi r$ ) is similar to the wavelength of visible light. If the crystals remain smaller, there is not enough contrast between the contrail and the background sky and the contrail stays invisible. Obviously the absolute humidity must be large enough such that tiny aerosol droplets can grow within about $40 \mathrm{~ms}$ to the critical size, and below $230 \mathrm{~K}$ there is usually not sufficient moisture available. Of course, the $230 \mathrm{~K}$ threshold is not a sharp boundary. It depends on pressure, temperature and humidity, wing depth and flight speed (the dynamical timescale). As it is not feasible to take all these factors into account, we simply take the $230 \mathrm{~K}$ threshold derived by Kärcher et al. (2009) as given. In contrast to aerodynamic contrails, exhaust contrails have no visibility threshold at this temperature because under these conditions about $99 \%$ of the water vapour in the exhaust plume at engine exit are contributed by the water that results from kerosene 


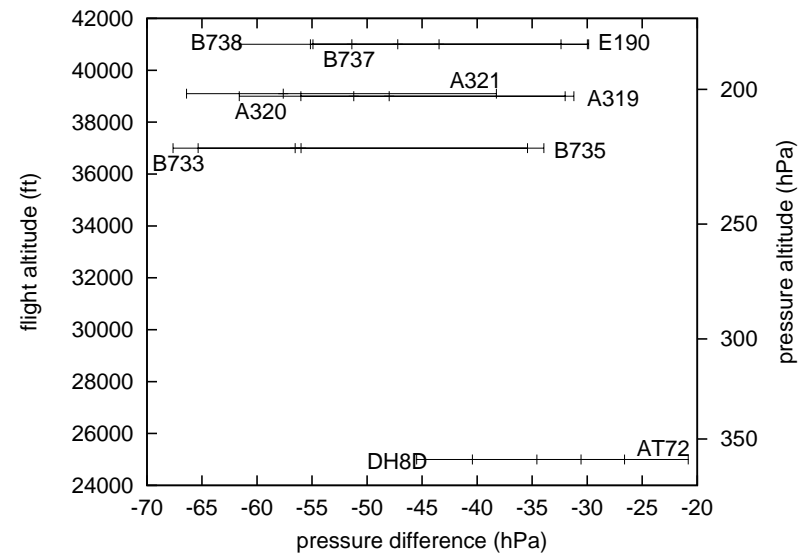

Fig. 1. Pressure differences $\Delta p$ above minus below the wings of various aircraft representing more than half of European air traffic in 2011. $\Delta p$ has been calculated by dividing weight by wing area. Error bars around a central reference value indicate pressure differences at maximum and minimum weights. Maximum flight altitudes in feet and corresponding pressure altitudes are given on the vertical axes. The aircraft types are: A320 (AIRBUS A-320), B738 (BOEING 737-800), A319 (AIRBUS A-319), A321 (AIRBUS A321), DH8D (DHC-8-400 DASH), B733 (BOEING 737-300), AT72 (ATR-72-200), B737 (BOEING 737-700), E190 (EMBRAER ERJ190), B735 (BOEING 737-500). Source: EUROCONTROL (1) EEC Technical/Scientific Report No. 12/06/21-55, 2012, and (2) BADA database (V327).

burning. This makes the contrail visible even under conditions where the ambient air is very dry.

Thus the minimum temperature at which visible aerodynamic contrails can be formed is $230 \mathrm{~K}$ and we have to determine the maximum temperature as that temperature at which the cooling over the wings suffices to bring the temperature below the supercooling limit of pure water, $235 \mathrm{~K}$. This maximum temperature depends on the ambient pressure, $p$, and the pressure drop, $\Delta p$, caused by the wing. This latter quantity can simply be calculated by dividing the aircraft weight by its wing area. It turns out that $-50 \mathrm{hPa}$ is a typical value for a wide range of aircraft (see Fig. 1), but in order to see the sensitivity of the maximum temperature on $\Delta p$ we will consider a range of -40 to $-60 \mathrm{hPa}$. Since the flow is adiabatic, temperature and pressure variations are connected via Poisson's laws, and we get

$T_{\max }(p, \Delta p)=235 \mathrm{~K}\left(1+\frac{\Delta p}{p}\right)^{\frac{1-\gamma}{\gamma}}$.

$\gamma=c_{p} / c_{V}=1.4$ is the adiabatic coefficient of air. Figure 2 shows the maximum temperature as a function of air pressure for three values of the pressure drop over the wing. Additionally it shows temperature profiles for various standard atmospheres. An example might be useful to explain the figure. At the $700 \mathrm{hPa}$ level it needs an ambient temperature of less than

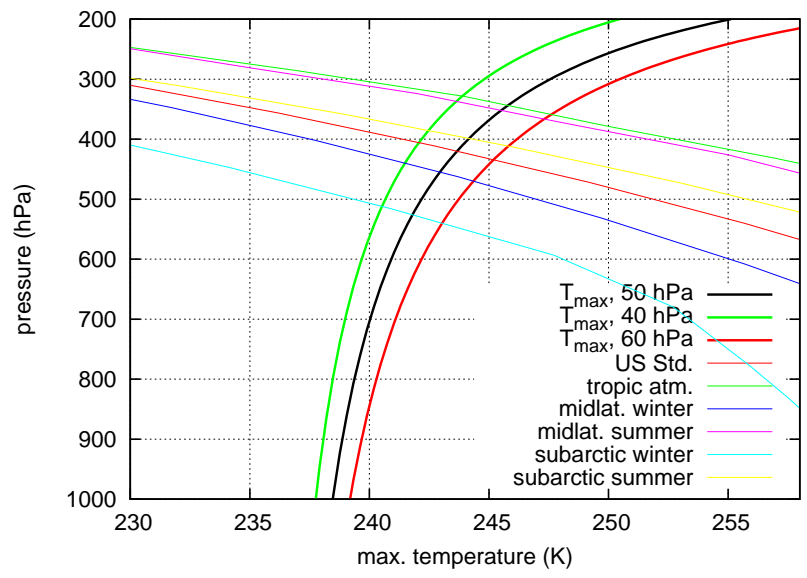

Fig. 2. Maximum temperature at which the airflow over a wing is cooled down to the supercooling limit of pure water $(235 \mathrm{~K})$ for three possible pressure drop values over the wing, as indicated in the legend (thick lines). The thin lines represent temperature profiles of various standard atmospheres, see legend.

$240 \pm 1 \mathrm{~K}$ to form an aerodynamic contrail. However, typically the atmosphere is much warmer than this on that level, even the subarctic winter temperature is more than $10 \mathrm{~K}$ too high on $700 \mathrm{hPa}$. Only when the ambient pressure is below approximately $540 \mathrm{hPa}$ (i.e. where the two bundles of curves start to cross each other) aerodynamic contrails are possible. The warmest standard atmosphere (i.e. the tropical one) reaches the minimum temperature of $230 \mathrm{~K}$ at $\sim 250 \mathrm{hPa}$. Thus we can state that aerodynamic contrails are possible between pressure levels of $\sim 250 \mathrm{hPa}-540 \mathrm{hPa}$. The ambient temperature will rarely be higher than $247.5 \mathrm{~K}$, the temperature where the maximum temperature curve for $-60 \mathrm{hPa}$ pressure drop intersects the tropical temperature profile.

These results can readily be applied to meteorological standard data: Fig. 3 shows for 27 June 2008, 12:00 UTC, where aerodynamic contrail formation was possible over Europe. An aerodynamic contrail was observed and photographed on that day over the island Norderney in northern Germany (Gierens et al., 2011). The data have been taken from the European Centre for Medium-Range Weather Forecasts (ECMWF) ERA Interim reanalysis $(24 \mathrm{~h}$ forecast initialised at 26 June 2008; 12:00 UTC; spatial resolution $0.5^{\circ} \times 0.5^{\circ}$; standard pressure levels 250 to $500 \mathrm{hPa}$ ). On the $250 \mathrm{hPa}$ level it is too cold for visible aerodynamic contrails to form over large parts of Europe. Only in the south, that is, over the Mediterranean and northern Africa it is warm enough. Over northern Europe there are confined regions with temperatures higher than $230 \mathrm{~K}$. Whether aerodynamic contrail formation is possible depends on whether this is tropospheric or stratospheric air; stratospheric air is possibly too dry to form visible aerodynamic contrails, independent of temperature (not yet tested). As the radiosonde Emden shows the thermal tropopause at $250 \mathrm{hPa}$ (see Gierens et al., 

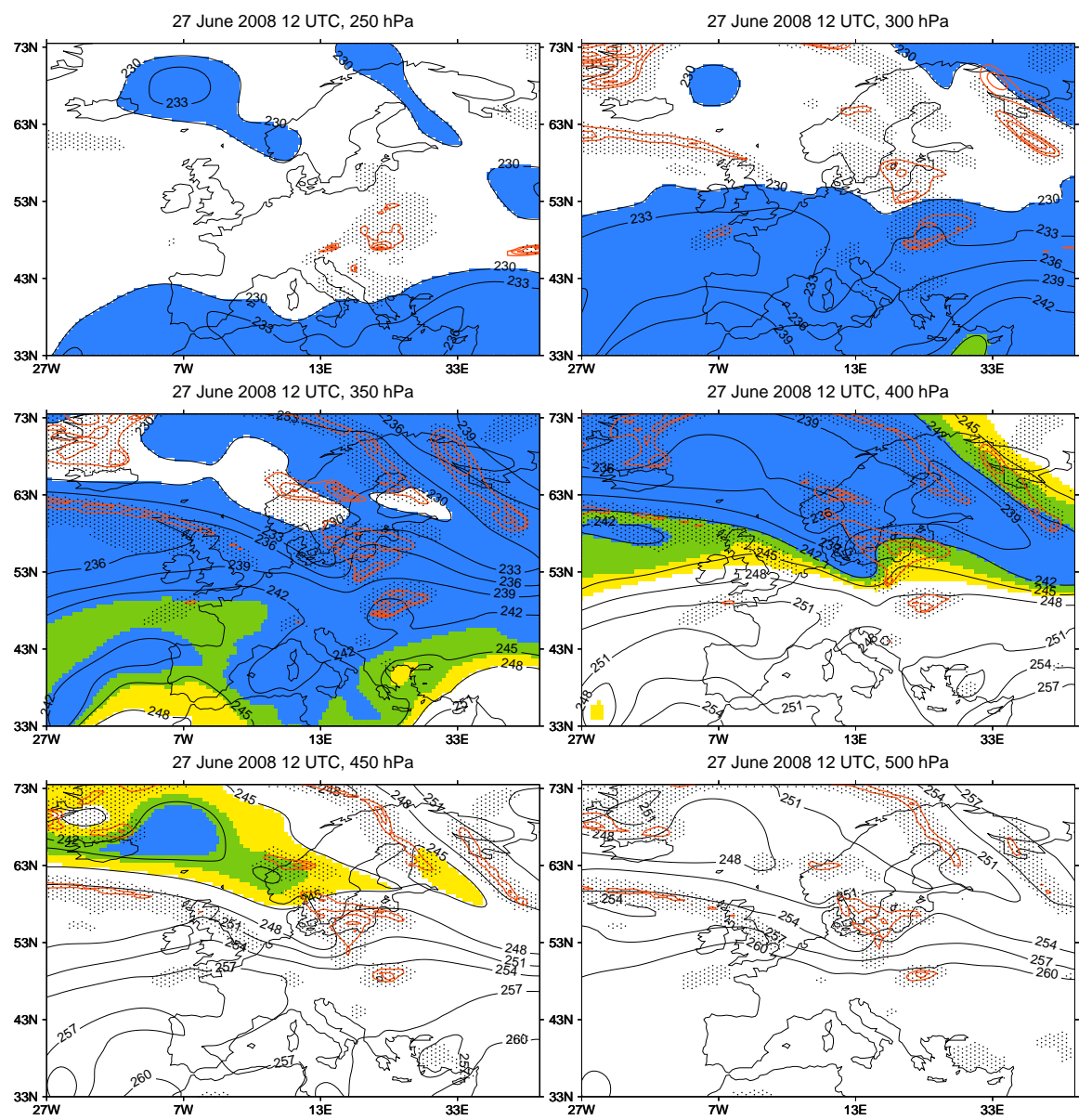

Fig. 3. Regions over Europe that are conditioned to formation of aerodynamic contrails on 27 June 2008, 12:00 UTC. White colour signifies too cold or too warm temperatures for aerodynamic contrail formation, the three colours correspond to pressure drop values of $-60,-50$, and $-40 \mathrm{hPa}$ (yellow, green, and blue, respectively). Stippling shows areas with clouds (cloud fraction exceeding 0.1 ), and the red contours mark ice supersaturated regions, with contour levels starting at ice saturation and incrementing by $5 \%$ relative humidity with respect to ice. Standard pressure levels increase from top left $(250 \mathrm{hPa})$ to bottom right $(500 \mathrm{hPa})$.

2011), these warm patches over northern Europe may well be stratospheric air. By following the pressure levels from 250 to $500 \mathrm{hPa}$, we observe that the regions where aerodynamic contrails can form first extend from south to north, on $350 \mathrm{hPa}$ most of the atmosphere over Europe can serve as an aerodynamic contrail formation region, but further below it is getting too warm from the south, on $400 \mathrm{hPa}$ only northern Europe (north of $53^{\circ} \mathrm{N}$ ) can see an aerodynamic contrail, and still further below this region shrinks until the formation of aerodynamic contrails is impossible everywhere on $500 \mathrm{hPa}$. At least for this special situation we have in some regions where aerodynamic contrails can form also ice supersaturated conditions such that ice formed aerodynamically can remain in the atmosphere without immediate sublimation after the passage of an aircraft. However, where we have ice supersaturation we have clouds as well, so the visibility of any persistent aerodynamic contrail is questionable and its effect on the local radiation balance probably low.
After this case study, it is now necessary to consider a longer period (say one complete year) and the global patterns of regions that are conditioned for formation of aerodynamic contrails.

\section{Climatology for the year 2011}

\subsection{Annual mean}

Again we use data from the ERA interim reanalysis for the set-up of a climatology. We use global $+24 \mathrm{~h}$ forecast data for the year 2011 in a horizontal resolution of $1^{\circ} \times 1^{\circ}$. We prefer the forecasts relative to the analyses, because a quick comparison using ten days in June 2011 showed that problems with supersaturation spin-up (Lamquin et al., 2009) are mitigated but seem not completely overcome. We consider three pressure levels sufficient and choose 250, 350, and $450 \mathrm{hPa}$. Using these data, we will study annual and 
seasonal distributions of regions where aerodynamic contrails can form for the year 2011.

The data analysis behind Fig. 4 includes only the temperature criteria, that is, it is not colder than $230 \mathrm{~K}$ and sufficiently cold that the temperature over the wings drops below $235 \mathrm{~K}$. Ice supersaturation and cloudiness conditions are not considered in Fig. 4, these considerations follow below. However, we have checked that the ambient relative humidity is everywhere sufficient that in the airflow over a wing the threshold for homogeneous nucleation is reached. For this threshold we use the following formula (Kärcher and Lohmann, 2002):

$S_{\text {crit }}=2.583-T_{\text {wing }} / 207.83$

where $T_{\text {wing }}$ is the temperature of the airflow over the wing. It turned out that the condition $S_{\text {wing }} \geq S_{\text {crit }}$ is always fulfilled. The saturation ratio over the wing is computed from that in the ambient air $S_{\text {amb }}$ with

$S_{\mathrm{wing}}=S_{\mathrm{amb}}\left(\frac{T_{\mathrm{wing}}}{T_{\mathrm{amb}}}\right)^{c_{p} / R_{a}} \frac{e^{*}\left(T_{\mathrm{amb}}\right)}{e^{*}\left(T_{\mathrm{wing}}\right)}$.

$e^{*}(T)$ is the saturation vapour pressure with respect to ice and the formulation of this function has been taken from Murphy and Koop (2005).

There is a general tendency of regions where aerodynamic contrails can form to shift from the tropics to polar regions with decreasing flight altitude (increasing pressure). Aerodynamic contrails form with higher than $50 \%$ probability only in the tropical belt on the $250 \mathrm{hPa}$ level (FL 340), roughly between $30^{\circ} \mathrm{S}$ and $30^{\circ} \mathrm{N}$. The transition to lower than $10 \%$ probability is rather sharp at these latitudes, caused by the poleward temperature decrease at the subtropical tropopause discontinuity. The temperatures at the lower flight levels $350 \mathrm{hPa}$ (FL 260 and lower) in the tropical belt allow almost no aerodynamic contrails to form; the temperature is usually too high there such that it will not drop below $235 \mathrm{~K}$ over an aircraft wing. North and south of the subtropics $\left( \pm 30^{\circ}\right)$ aerodynamic contrails can form on pressure levels $350 \mathrm{hPa}$ and below, and contrail formation at $450 \mathrm{hPa}$ is confined to the polar zone regions north and south of $\pm 45^{\circ}$. The probability values are quite high for the $250 \mathrm{hPa}$ level in the tropics, mostly exceeding $80 \%$. Such high probabilities are also present at several locations in the northern extra-tropics on the $350 \mathrm{hPa}$ pressure level, seemingly connected but east of the Atlantic and Pacific storm tracks, while otherwise and on the $450 \mathrm{hPa}$ level the probabilities are generally lower than $60 \%$. In the Southern Hemisphere, on the contrary, high probabilities occur on both lower pressure levels through all longitudes, and values lower than $50 \%$ are only present over Antarctica. The latter is, however, merely an academic result since there is hardly any aviation in the southern extratropics.

Looking back at Fig. 1 it seems that the standard flight altitudes of eight of the most common aircraft are above the maximum altitude where aerodynamic contrails become visible. Only two of the ten aircraft are usually at an appropriate flight level, but these have lower pressure difference, around $-30 \mathrm{hPa}$. If this smaller pressure difference were typical for the formation of aerodynamic contrails instead of our standard assumption of $-50 \mathrm{hPa}$, then the maximum temperature at which aerodynamic contrails form would decrease. We have recalculated the global map of Fig. 4 for the smaller pressure change of $-30 \mathrm{hPa}$ (not shown). On $250 \mathrm{hPa}$ there is almost no effect, which means that the ambient temperatures are generally low enough that the temperature threshold does not matter. On the two lower levels, however, the probability values for aerodynamic contrail formation are decreased in many locations by about 0.1 . Yet the patterns on the maps are very similar to those in Fig. 4. As a quick check of the next ten aircraft in the BADA (Base of Aircraft Data, see EUROCONTROL, 2013) database reveals that only a small fraction of important aircraft have indeed this low pressure change, we stay for the remaining analysis with our standard pressure change value of $-50 \mathrm{hPa}$.

\subsection{Seasonal variation}

Since the formation conditions of aerodynamic contrails depend strongly on ambient temperature, we expect large seasonal variability in their frequency or probability of occurrence. This is shown in Fig. 5 again for 2011. The figure displays zonal mean probabilities for occurrence of appropriate conditions that would allow formation of aerodynamic contrails. We see large seasonal variations and again large differences on the considered pressure levels, as before. The seasonal variation is weak on the $250 \mathrm{hPa}$ level, as expected, since aerodynamic contrails form almost only in the tropics on this level and the seasons are weakly pronounced there. More variation is found outside of the tropics (equatorward of $\pm 20^{\circ}$ ), where the probability values drop sharply. It is worth mentioning that the probability for formation of AerC reaches unity in boreal summer and fall at about $10^{\circ} \mathrm{N}$, roughly along and just north of the intertropical convergence zone. Note, that this maximum is not caused by the moisture brought up to $250 \mathrm{hPa}$ by convection, since we considered only the temperature criteria for the construction of the figure.

The seasonal variation is much stronger on the lower pressure levels where aerodynamic contrails form exclusively in the extra-tropics, poleward of $\pm 15^{\circ}$. The zonal probability curves have one peak in each hemisphere, and these peaks shift characteristically poleward and equatorward with the seasons. In the respective summer months the probability peaks shift poleward, while they shift equatorward in the respective winter. This shifting is relatively distinct on $350 \mathrm{hPa}$, but less so on $450 \mathrm{hPa}$. The equatorward shift in the winter is explained by frequent too cold conditions in polar latitudes on $350 \mathrm{hPa}$. On $450 \mathrm{hPa}$ it is often sufficiently warm 

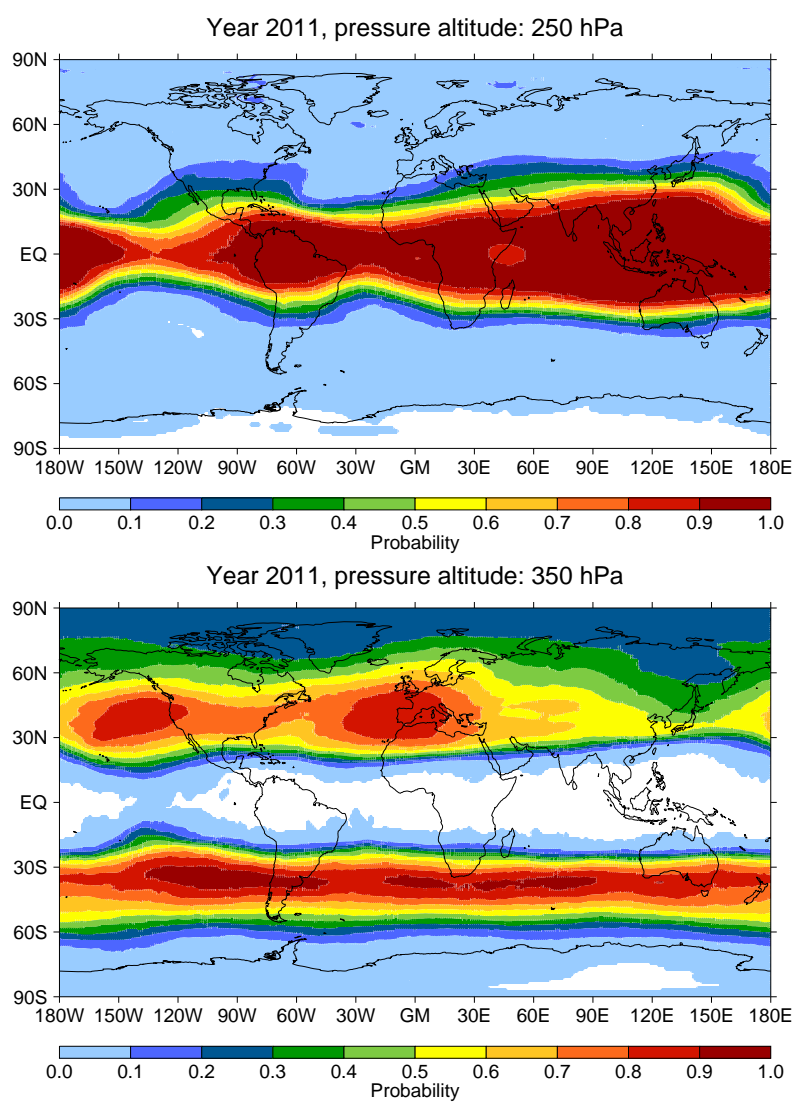

Year 2011, pressure altitude: $450 \mathrm{hPa}$

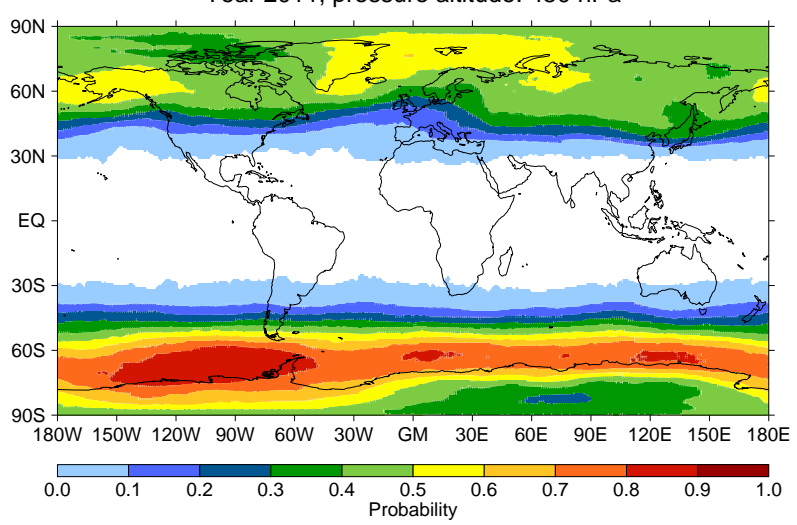

Fig. 4. Global distribution of regions that are conditioned to formation of aerodynamic contrails in 2011 for three pressure levels, 250, 350 , and $450 \mathrm{hPa}$ (from top to bottom). Only temperature criteria are considered for this figure.

for aerodynamic contrails to become visible at the poles in all seasons.

Next, we have to consider where, when and how much aviation occurs in the regions where aerodynamic contrails can form. For this purpose we use data of flown kilometres per $1^{\circ} \times 1^{\circ} \times 610 \mathrm{~m}$ grid box and per month from the aviation inventory for the year 2000 produced within the European FP6 project QUANTIFY (see http://www.ip-quantify.eu). The air
Year 2011, pressure altitude: $250 \mathrm{hPa}$

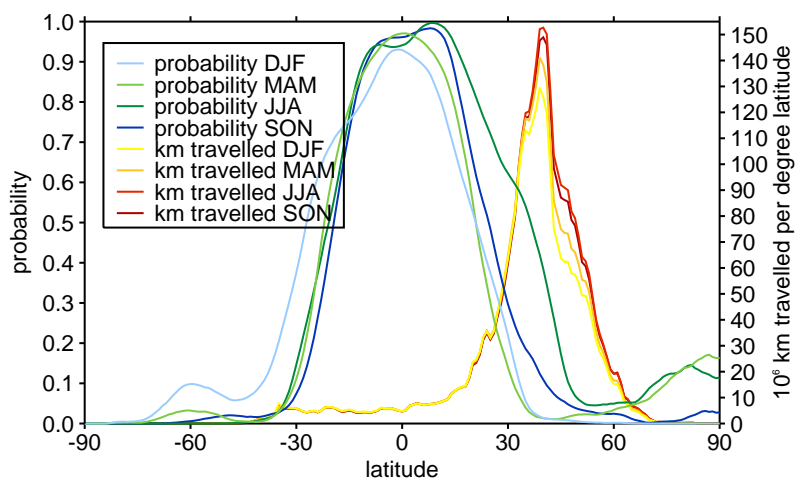

Year 2011, pressure altitude: $350 \mathrm{hPa}$

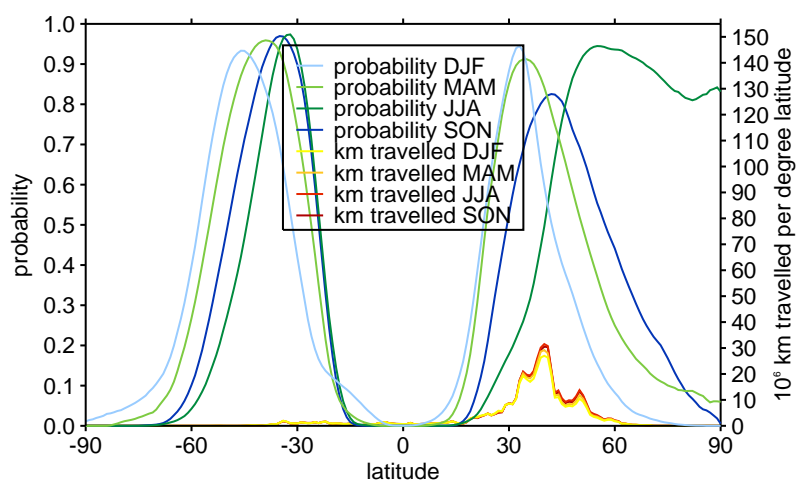

Year 2011, pressure altitude: $450 \mathrm{hPa}$

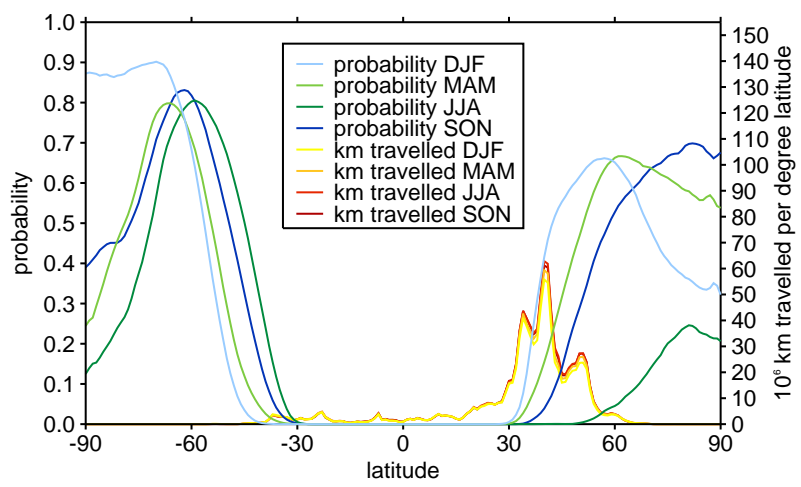

Fig. 5. Seasonal variation of zonally averaged probability that an aircraft with $\Delta p=50 \mathrm{hPa}$ produces an aerodynamic contrail when flying on the indicated pressure level, 250, 350, and $450 \mathrm{hPa}$ (from top to bottom). Only temperature criteria are considered for this figure. Furthermore the seasonal and latitudinal distribution of air traffic at about the indicated pressure level is shown in the figure.

traffic data for three adjacent altitude ranges per pressure level have been included in Fig. 5 as well. Thus, each pressure level is identified here with a range of six flight levels (air routes vertically stacked in $10 \mathrm{hft}$, i.e. $305 \mathrm{~m}$, distance). This is done for illustration only and we do not claim that 
these flight levels exactly match the pressure levels selected. In detail, the following identification has been made: flight levels 4880 to $6710 \mathrm{~m}$ belong to $450 \mathrm{hPa}, 6710$ to $8540 \mathrm{~m}$ to $350 \mathrm{hPa}$, and 8540 to $10370 \mathrm{~m}$ to $250 \mathrm{hPa}$. As expected, we find most traffic in the Northern Hemisphere with a maximum due to intercontinental flights on the $250 \mathrm{hPa}$ level, a local minimum at $350 \mathrm{hPa}$, and a second but weaker maximum (regional flights) at $450 \mathrm{hPa}$. On the $250 \mathrm{hPa}$ level we see that the probability maximum for aerodynamic contrails in the tropics is of little effect since most of the air traffic occurs where the probability values for aerodynamic contrails sharply drop due to too low ambient temperatures. The traffic maximum falls directly into the region where aerodynamic contrails can form on the $350 \mathrm{hPa}$ level, however, with only little air traffic. The slightly higher amount of air travel on the $450 \mathrm{hPa}$ level occurs a bit south of the region where aerodynamic contrails would form and the traffic and the probability curves do not completely overlap. This overlap, which is an approximate measure for the total possible amount (length) of aerodynamic contrails on a pressure level, can simply be quantified by multiplying the traffic data with the probabilities for aerodynamic contrail formation and integrating this over the globe. The result is presented in Table 1, which shows (i) the total flight distances on the respective flight levels, (ii) the flight distances where the formation of aerodynamic contrails is possible, and (iii) the ratio of these numbers, that is, the fraction of flight distances where aerodynamic contrails can be produced. We find the following: Although there is very much more traffic at about $250 \mathrm{hPa}$ than on $350 \mathrm{hPa}$, there is not much more aerodynamic contrail production on 250 than on $350 \mathrm{hPa}$ (perhaps with the exception of the northern winter months, when the conditions are best on $250 \mathrm{hPa}$ ). Furthermore, in spite of more traffic on $450 \mathrm{hPa}$ than on $350 \mathrm{hPa}$, there are generally more aerodynamic contrails on 350 than on $450 \mathrm{hPa}$ (with the exception of the northern summer months when the conditions are optimal on $450 \mathrm{hPa}$ ). Much higher fractions of flight distance allow formation of aerodynamic contrails on the $350 \mathrm{hPa}$ level than on the two other levels. The seasonal variation is quite strong on all levels, which is mainly a result of the shifting weather patterns.

\subsection{Persistent aerodynamic contrails}

Like exhaust contrails, aerodynamic contrails can only persist for a long time (hours) if the ambient air is supersaturated with respect to ice. Thus we add a new condition, namely $\mathrm{RHi} \geq 100 \%$, to the temperature conditions. The results are shown in Fig. 6 using the same colour coding as before for a convenient comparison. We find that conditions for persistent aerodynamic contrails are mostly given in less than $20 \%$ of the time, only over the Indonesian warm pool there are higher probabilities, reaching 30-40\%. Although the reduction of the probability values from the consideration above, only using the temperature criteria, to the inclusion of the supersatu-
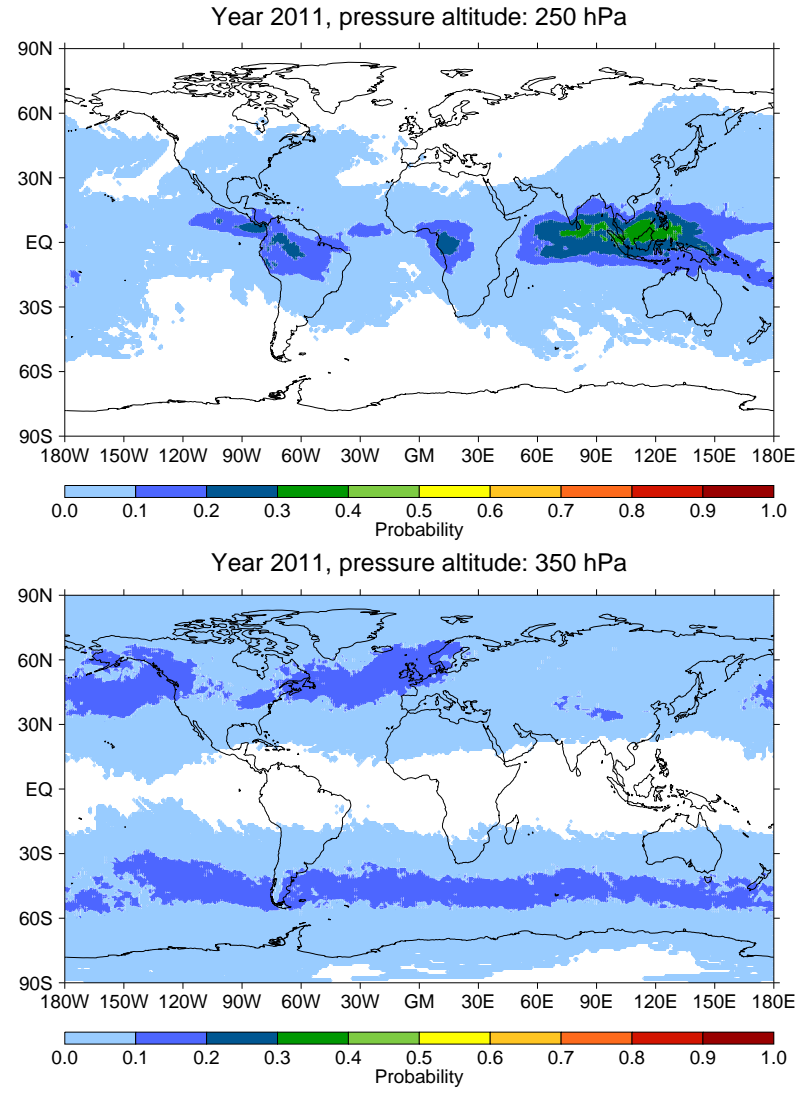

Year 2011, pressure altitude: $450 \mathrm{hPa}$

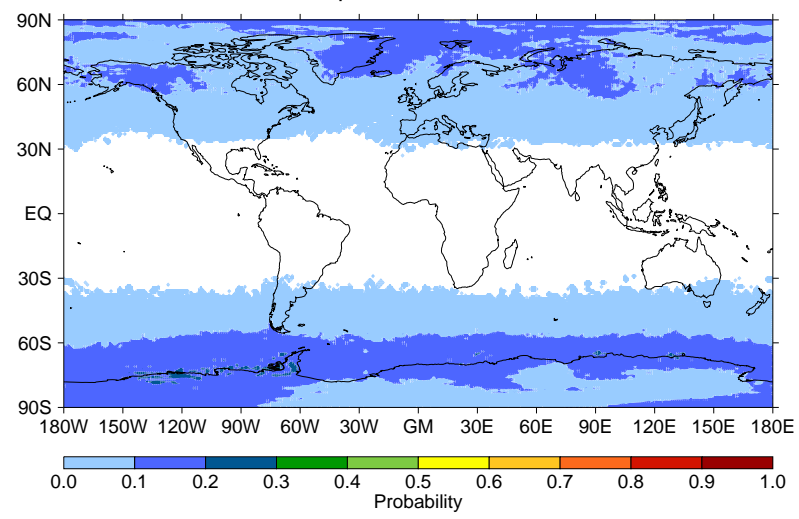

Fig. 6. As Fig. 4, but only regions where an aerodynamic contrail would be persistent (i.e. where the ambient air is ice supersaturated) are shown.

ration criterion is rather strong, the result is no surprise. It is well known that the current aircraft fleet meets ice supersaturation in less than $15 \%$ of its flight time or distance (Gierens et al., 1999), thus the current result is consistent with the earlier findings.

Table 2 contains the total flight distances with persistent aerodynamic contrails on the respective pressure level in the year 2011 and the ratios of these distances to the total flight distances, as before. These probability values are less than 
Table 1. 1st part - total flight distances (in $\mathrm{km}$ ) on the respective flight levels; 2nd part - flight distances with the possibility of aerodynamic contrail formation; 3rd part - fractions of the total flight distances where aerodynamic contrail formation is possible.

\begin{tabular}{lrrrr}
\hline Total & Dec/Jan/Feb & Mar/Apr/May & Jun/Jul/Aug & Sep/Oct/Nov \\
\hline $250 \mathrm{hPa}$ & $3.01 \times 10^{9}$ & $3.20 \times 10^{9}$ & $3.46 \times 10^{9}$ & $3.37 \times 10^{9}$ \\
$350 \mathrm{hPa}$ & $4.60 \times 10^{8}$ & $4.85 \times 10^{8}$ & $5.16 \times 10^{8}$ & $5.01 \times 10^{8}$ \\
$450 \mathrm{hPa}$ & $9.18 \times 10^{8}$ & $9.68 \times 10^{8}$ & $1.02 \times 10^{9}$ & $1.00 \times 10^{9}$ \\
\hline Total AerC & & & & \\
\hline $250 \mathrm{hPa}$ & $8.91 \times 10^{8}$ & $4.27 \times 10^{8}$ & $4.99 \times 10^{8}$ & $4.51 \times 10^{8}$ \\
$350 \mathrm{hPa}$ & $3.03 \times 10^{8}$ & $3.68 \times 10^{8}$ & $2.80 \times 10^{8}$ & $3.52 \times 10^{8}$ \\
$450 \mathrm{hPa}$ & $3.23 \times 10^{7}$ & $7.38 \times 10^{7}$ & $3.15 \times 10^{8}$ & $1.77 \times 10^{8}$ \\
\hline Frac AerC & & & & \\
\hline $250 \mathrm{hPa}$ & 0.30 & 0.13 & 0.14 & 0.13 \\
$350 \mathrm{hPa}$ & 0.66 & 0.76 & 0.54 & 0.70 \\
$450 \mathrm{hPa}$ & 0.04 & 0.08 & 0.31 & 0.18 \\
\hline
\end{tabular}

Table 2. Flight distances with persistent aerodynamic contrails: 1 st part - flight distances in km; 2 nd part - fractions of the total flight distances where aerodynamic contrails would be persistent.

\begin{tabular}{lrrrr}
\hline Total pers. AerC & Dec/Jan/Feb & Mar/Apr/May & Jun/Jul/Aug & Sep/Oct/Nov \\
\hline $250 \mathrm{hPa}$ & $6.37 \times 10^{7}$ & $3.16 \times 10^{7}$ & $2.77 \times 10^{7}$ & $3.08 \times 10^{7}$ \\
$350 \mathrm{hPa}$ & $2.63 \times 10^{7}$ & $4.27 \times 10^{7}$ & $3.54 \times 10^{7}$ & $4.00 \times 10^{7}$ \\
$450 \mathrm{hPa}$ & $2.49 \times 10^{6}$ & $6.31 \times 10^{6}$ & $3.16 \times 10^{7}$ & $1.47 \times 10^{7}$ \\
\hline Frac pers. AerC & & & & \\
\hline $250 \mathrm{hPa}$ & 0.02 & 0.01 & 0.01 & 0.01 \\
$350 \mathrm{hPa}$ & 0.06 & 0.09 & 0.07 & 0.08 \\
$450 \mathrm{hPa}$ & 0.003 & 0.01 & 0.03 & 0.01 \\
\hline
\end{tabular}

$3 \%$ on both 250 and $450 \mathrm{hPa}$ and less than $10 \%$ on the intermediate pressure level.

Gierens et al. (2009) discuss the possibility that ice crystals in aerodynamic contrails could be less stable than ice crystals in cirrus clouds due to the special formation and initial growth conditions. Cooling rates of $\mathcal{O}\left(10^{4}\right) \mathrm{K} \mathrm{s}^{-1}$ occur over the wings, and similar cooling rates are used in laboratories to hyper-quench micron-sized water droplets to form amorphous ice (Murray et al., 2005), but at much lower than tropospheric temperatures. Thus it is not clear whether the ice that forms over wings is amorphous and if so, for what time period. Amorphous ice can gradually crystallise to cubic ice Ic, the faster the higher the ambient temperature (Bartels-Rausch et al., 2012). In turn, cubic ice transforms into the usual form of hexagonal ice within minutes or on longer timescales at middle and upper tropospheric temperatures (Murphy, 2003; Murray et al., 2005). It is possible that aerodynamic contrails consist of a mixture of cubic and hexagonal ice many kilometres behind an aircraft which would imply a higher than usual saturation vapour pressure for aerodynamic contrails, because saturation for cubic ice occurs only at 103 to $110 \%$ relative humidity over hexago- nal ice. If this is indeed the case then aerodynamic contrails will be persistent only at these higher relative humidities and thus be even less frequent than shown in Table 2 .

Finally, we compare the numbers of Tables 1 and 2 and with corresponding numbers for exhaust contrails in Table 3. These have been computed from the QUANTIFY inventory as above, but using the Schmidt-Appleman criterion (Schumann, 1996) instead of the criteria for aerodynamic contrails. The persistence criterion is the same, namely ice supersaturation of the ambient air. To our knowledge, this kind of quantity (fraction of flight distance where contrails or persistent contrails are produced) has only been computed by Rädel and Shine (2008, their Fig. 2) and Schumann et al. (2011, their Table 1), because usually one prefers to deal with coverage and potential coverage (for the latter notion, see Sausen et al., 1998). As expected from earlier work we find the largest probability for formation of exhaust contrails and persistent exhaust contrails on the $250 \mathrm{hPa}$ level with a strong reduction at lower altitudes. This tendency results from the fact that low temperature favours formation of exhaust contrails. Thus, this behaviour is to some degree opposite to the formation conditions of aerodynamic contrails. 
Table 3. Flight distances with exhaust contrails and persistent exhaust contrails: 1st part - flight distances with exhaust contrails in km; 2nd part - fractions of flight distances with exhaust contrails; 3rd part - flight distances with persistent exhaust contrails in km; 4th part fractions of the total flight distances where exhaust contrails would be persistent.

\begin{tabular}{lrrrr}
\hline Total ex. Con. & Dec/Jan/Feb & Mar/Apr/May & Jun/Jul/Aug & Sep/Oct/Nov \\
\hline $250 \mathrm{hPa}$ & $9.38 \times 10^{8}$ & $1.81 \times 10^{9}$ & $2.21 \times 10^{9}$ & $1.86 \times 10^{9}$ \\
$350 \mathrm{hPa}$ & $7.56 \times 10^{6}$ & $1.85 \times 10^{7}$ & $9.18 \times 10^{7}$ & $3.98 \times 10^{7}$ \\
$450 \mathrm{hPa}$ & $3.29 \times 10^{5}$ & $2.64 \times 10^{6}$ & $1.12 \times 10^{7}$ & $5.00 \times 10^{6}$ \\
\hline Frac ex. Con. & & & & \\
\hline $250 \mathrm{hPa}$ & 0.31 & 0.57 & 0.64 & 0.55 \\
$350 \mathrm{hPa}$ & 0.02 & 0.04 & 0.18 & 0.08 \\
$450 \mathrm{hPa}$ & 0.00 & 0.00 & 0.01 & 0.00 \\
\hline Total pers. ex. Con. & & & & \\
\hline $250 \mathrm{hPa}$ & $1.51 \times 10^{8}$ & $3.18 \times 10^{8}$ & $2.31 \times 10^{8}$ & $2.42 \times 10^{8}$ \\
$350 \mathrm{hPa}$ & $1.64 \times 10^{6}$ & $3.52 \times 10^{6}$ & $1.86 \times 10^{7}$ & $8.23 \times 10^{6}$ \\
$450 \mathrm{hPa}$ & $1.01 \times 10^{5}$ & $7.89 \times 10^{5}$ & $2.35 \times 10^{6}$ & $1.21 \times 10^{6}$ \\
\hline Frac pers. ex. Con. & & & & \\
\hline $250 \mathrm{hPa}$ & 0.05 & 0.10 & 0.07 & 0.07 \\
$350 \mathrm{hPa}$ & 0.00 & 0.01 & 0.04 & 0.02 \\
$450 \mathrm{hPa}$ & 0.00 & 0.00 & 0.00 & 0.00 \\
\hline
\end{tabular}

While we have maxima of exhaust contrails on the $250 \mathrm{hPa}$ level, the maxima of aerodynamic contrails are given on the $350 \mathrm{hPa}$ level. This holds for both short-lived and persistent contrails. On $450 \mathrm{hPa}$ exhaust contrails do practically not appear while aerodynamic ones are quite often produced in summer and autumn, but they are mostly short-lived. The altitude region between 350 and $250 \mathrm{hPa}$ appears to offer the possibility that aerodynamic and exhaust contrails may form together, where they might coexist. How often this is possible will thus be considered next.

\subsection{Coexistence of aerodynamic and exhaust contrails}

We have checked whether and how often in 2011 it was possible that aerodynamic and exhaust contrails could form simultaneously. Persistence was not accounted for in this check as it would dwarf the values found still further. The results for the three pressure levels are shown in Fig. 7. Generally, coexistence of the two kinds of contrails is a rare phenomenon, in our data it is even almost impossible on the $250 \mathrm{hPa}$ level. On the two lower levels coexistence is sometimes possible in the extratropics, with probabilities not exceeding $10 \%$ (except for a region in Antarctica which is irrelevant). The map is very noisy for the $350 \mathrm{hPa}$ level because the probability values are indeed close to zero, so exact zero (white) and close to zero (light blue) appear randomly distributed. On $450 \mathrm{hPa}$ there is in principle more substantial possibility for the coexistence of both contrail types, but Table 3 shows that exhaust contrail formation is extremely seldom on this level, because aircraft on this altitude often fly in regions where the Schmidt-Appleman criterion is not fulfilled (e.g. equatorwards of $\pm 40^{\circ}$ ).

Thus we conclude this section with the statement that coexistence of exhaust and aerodynamic contrails is not impossible but very improbable.

\section{Conclusions}

In the present study we have analysed atmospheric conditions that allow the formation of aerodynamic contrails which have been defined as line shaped ice clouds that visibly appear at the wings of aircraft in cruise or close to it such that no doubt exists on its formation by the adiabatic cooling of the air flow over the wing. Although only one year of weather data has been analysed (2011), we deem that our conclusions are not affected by any special conditions that might have held in 2011. From this study we can draw the following general conclusions:

- Visible aerodynamic contrails are possible in a thick layer extending from $\sim 540$ to $250 \mathrm{hPa}$. These pressure levels are determined by two temperature thresholds. Below $230 \mathrm{~K}$ aerodynamic contrails generally stay invisible because there is insufficient water vapour to condense on the ice crystals (Kärcher et al., 2009). The high temperature threshold is determined by the requirement that the airflow over the wing must cool down to at least the supercooling limit of pure water droplets, $235 \mathrm{~K}$, such that droplets freeze. This threshold is given in Eq. (1). It depends on the ambient 

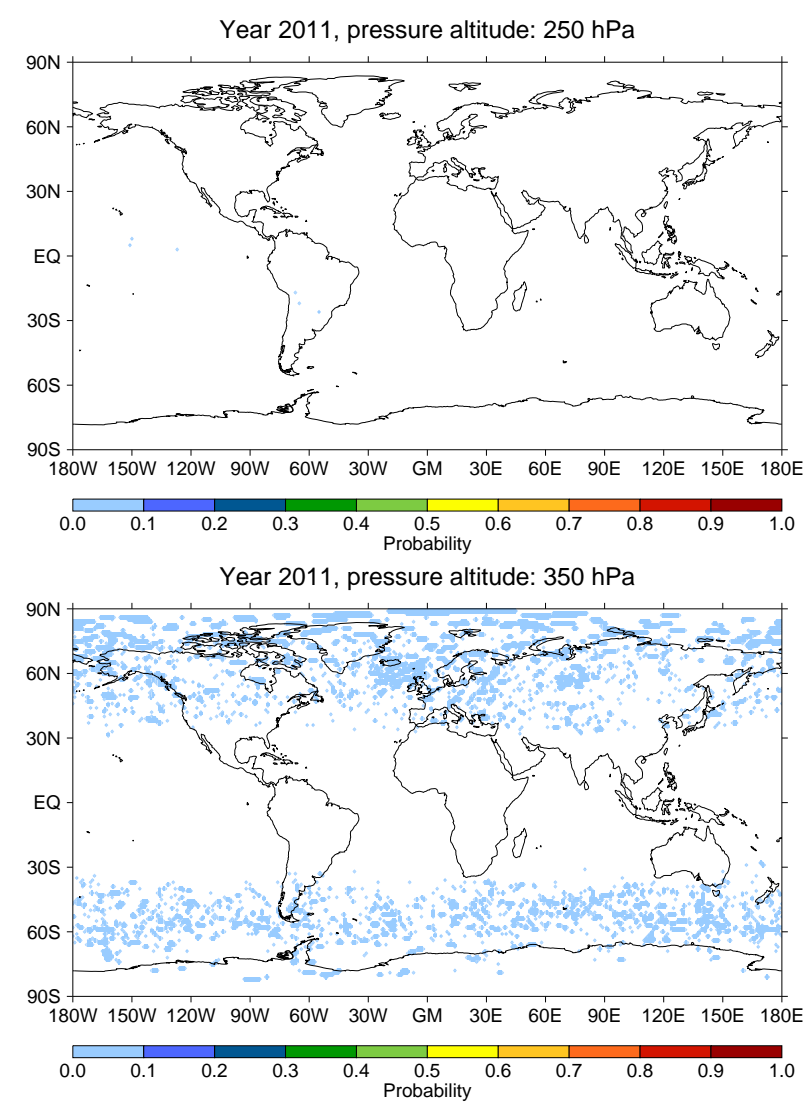

Year 2011, pressure altitude: $450 \mathrm{hPa}$

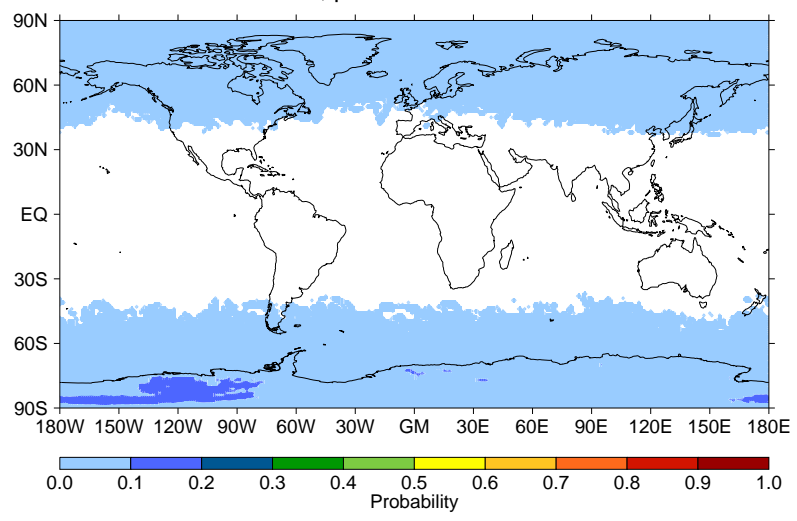

Fig. 7. Regions where aerodynamic and exhaust contrails can form simultaneously together with the respective probabilities are shown for the three pressure levels 250,350 , and $450 \mathrm{hPa}$ (from top to bottom). Persistence (i.e. ice supersaturation) was not accounted for.

pressure and the pressure change over the wing, and because of the latter it depends on aircraft type and its current weight.

- Too low ambient relative humidity is almost no constraint for the possibility to form aerodynamic contrails because the saturation water vapour pressure over the wings is almost always lowered sufficiently that water saturation occurs in the airflow.
- The altitude range where aerodynamic contrails can form declines from the tropics to the poles. In the tropics it is highest $(250 \mathrm{hPa}$, typical for intercontinental and continental flights), in the extratropics and polar latitudes it is lower ( 350 and $450 \mathrm{hPa}$, continental and regional flights).

- The formation probabilities reach quite high values locally, but regions of high formation probabilities differ from regions with strong air traffic.

- Latitude bands where aerodynamic contrails can form shift in the course of the seasons because of the shift of the threshold isotherms.

- Persistent aerodynamic contrails are rare. Generally they occur with less than $10 \%$ probability, but more typically this probability is of the order $1 \%$. These values could indeed be even lower because aerodynamic contrails may well consist of metastable forms of ice (e.g. cubic or amorphous ice due to their special formation conditions which are similar to hyper-quenching of cold micron sized droplets in the laboratory).

- Coexistence of aerodynamic contrails with exhaust contrails is possible but very improbable.

The most important question is whether aerodynamic contrails have an adverse effect on climate. From the results in this study we deem that a climate effect of aerodynamic contrails is currently considerably smaller than the climate effect of exhaust contrails, but it adds to it. This conclusion issues from the following argument: the contrail climate effect originates most from contrails at about $10 \mathrm{~km}$ altitude, about $250 \mathrm{hPa}$. Contrails at lower altitudes contribute much less (Rädel and Shine, 2008). At $250 \mathrm{hPa}$ there are currently many more exhaust contrails than aerodynamic contrails (see the absolute values in the tables), thus exhaust contrails must have the lion's share in contrail climate impact. This may change in the future when more air traffic will occur in tropical latitudes.

Acknowledgements. We thank Bethan Owen and David Lee from the Manchester Metropolitan University for setting up the QUANTIFY air traffic inventory. The meteorological data have been obtained from the European Centre for Medium-Range Weather Forecasts (ECMWF) within the Special Project spdeissr. Furthermore we thank Eurocontrol for permission to use BADA data for our institute's research. Kaspar Graf and Andy Heymsfield made comments to an early version that helped to improve the logic and the readability of the paper. The editor and two reviewers helped to improve language and style. This work contributes to the new DLR project WeCare.

The service charges for this open access publication have been covered by a Research Centre of the Helmholtz Association. 
Edited by: P. Haynes

\section{References}

Bartels-Rausch, T., Bergeron, V., Cartwright, J., Escribano, R., Finney, J., Grothe, H., Gutiérrez, P., Haapala, J., Kuhs, W., Pettersson, J., Price, S., Sainz-Díaz, C., Stokes, D., Strazzulla, G., Thomson, E., Trinks, H., and Uras-Aytemiz, N.: Ice structures, patterns, and processes: A view across the icefields, Rev. Modern Phys., 84, 885-944, 2012.

Burkhardt, U. and Kärcher, B.: Global radiative forcing from contrail cirrus, Nature Clim. Change, 1, 54-58, 2011.

EUROCONTROL: User manual for the Base of Aircraft Data (BADA) revision 3.10, Tech. Rep. EEC Technical/Scientific Report No. 12/04/10-45, EUROCONTROL Experimental Centre, 2013.

Gierens, K., Schumann, U., Helten, M., Smit, H., and Marenco, A.: A distribution law for relative humidity in the upper troposphere and lower stratosphere derived from three years of MOZAIC measurements, Ann. Geophys., 17, 1218-1226, doi:10.1007/s00585-999-1218-7, 1999.

Gierens, K., Kärcher, B., Mannstein, H., and Mayer, B.: Aerodynamic contrails: Phenomenology and flow physics, J. Atmos. Sci., 66, 217-226, 2009.

Gierens, K., Kästner, M., and Klatt, D.: Iridescent aerodynamic contrails: The Norderney case of 27 June 2008, Meteorol. Z., 20, 305-311, 2011.

Kärcher, B. and Lohmann, U.: A parameterization of cirrus cloud formation: Homogeneous freezing of supercooled aerosols, J. Geophys. Res., 107, doi:10.1029/2001JD000470, 2002.

Kärcher, B., Mayer, B., Gierens, K., Burkhardt, U., Mannstein, H., and Chatterjee, R.: Aerodynamic contrails: Microphysics and optical properties, J. Atmos. Sci., 66, 227-243, 2009.
Lamquin, N., Gierens, K., Stubenrauch, C. J., and Chatterjee, R.: Evaluation of upper tropospheric humidity forecasts from ECMWF using AIRS and CALIPSO data, Atmos. Chem. Phys., 9, 1779-1793, doi:10.5194/acp-9-1779-2009, 2009.

Lee, D., Fahey, D., Forster, P., Newton, P., Wit, R., Lim, L. L., Owen, B., and Sausen, R.: Aviation and global climate change in the 21st century, Atmos. Environ., 43, 3520-3537, 2009.

Lee, D., Pitari, G., Grewe, V., Gierens, K., Penner, J., Petzold, A., Prather, M., Schumann, U., Bais, A., Berntsen, T., Iachetti, D., Lim, L., and Sausen, R.: Transport impacts on atmosphere and climate: Aviation, Atmos. Environ., 44, 4678-4734, 2012.

Murphy, D. and Koop, T.: Review of the vapour pressures of ice and supercooled water for atmospheric applications, Quart. J. Roy. Met. Soc., 131, 1539-1565, 2005.

Murphy, D. M.: Dehydration in cold clouds is enhanced by a transition from cubic to hexagonal ice, Geophys. Res. Lett., 30, 2230, doi:10.1029/2003GL018566, 2003.

Murray, B., Knopf, D., and Bertram, A.: The formation of cubic ice under conditions relevant to Earth s atmosphere, Nature, 434, 202-205, 2005.

Rädel, G. and Shine, K.: Radiative forcing by persistent contrails and its dependence on cruise altitudes, J. Geophys. Res., 113, D07105, doi:10.1029/2007JD009117, 2008.

Sausen, R., Gierens, K., Ponater, M., and Schumann, U.: A diagnostic study of the global distribution of contrails, Part I. Present day climate, Theor. Appl. Climatol., 61, 127-141, 1998.

Schumann, U.: On conditions for contrail formation from aircraft exhausts, Meteorol. Z., 5, 4-23, 1996.

Schumann, U., Graf, K., and Mannstein, H.: Potential to reduce climate impact of aviation by flight level changes, in: 3rd AIAA Atmospheric Space Environments Conference, 27-30 June 2011, Honolulu, Hawaii, 3376, 1-22, doi:10.2514/6.2011-3376, 2011. 